Обоснование. Опухоли грудной клетки, вовлекающие стенку верхней полой вены (ВПВ), нередко встречаются в практике торакального хирурга, занимающегося лечением онкологических больных. Выполнение расширенных комбинированных операций, позволяющих удалить опухолевую ткань в полном объеме, улучшает общую и безрецидивную выживаемость больных и тем самым оправдано с онкологических позиций. У ряда больных в связи с длительно существующим синдромом ВПВ развитие венозных коллатералей создает повышенные риски тромбирования протеза в раннем послеоперационном периоде. В этом случае возможно выполнение циркулярной резекции ВПВ без ее последующего протезирования. Цель - изучить непосредственные результаты резекции ВПВ у больных с опухолевой патологией грудной клетки, разработать алгоритм и выделить группу больных, у которых возможна циркулярная резекция ВПВ без протезирования. Материал и методы. В исследование вошли 28 пациентов (22 мужчины, 6 женщин; средний возраст - 55 (от 21 до 70) лет), которым за 10-летний период (с 2008 по 2018 г.) была выполнена резекция ВПВ в ходе хирургического вмешательства по поводу злокачественной опухоли легкого или средостения в отделении торакальной хирургии МНИОИ им. П.А. Герцена. Были проанализированы непосредственные результаты операции, течение послеоперационного периода, технические особенности выполнения операции. Результаты. Местнораспространенный рак легкого диагностирован у 19 (67\%) больных, тимома - у 3 (10\%), метастатическое поражение легкого - у 2 (7\%), герминогенная опухоль средостения - у 2 (7\%), рак тимуса - у 1 (3\%), резидуальная лимфома (медиастинальная В-клеточная лимфома) у 1 (3\%) больного. У большинства больных в 15 (53\%) случаях - опухолевый процесс носил осложненный характер. У 4 больных с длительно существующим синдромом ВПВ выполнена циркулярная резекция ВПВ без протезирования. У 22 пациентов (78\%) течение послеоперационного периода носило неосложненный характер. Послеоперационная летальность составила 7\%. Заключение. Резекция ВПВ может быть безопасно выполнена у пациентов с первичными опухолями средостения и легкого. При длительно существующем синдроме ВПВ развившиеся кава-кавальные анастомозы берут на себя ее значительную функцию, при этом циркулярная резекция ВПВ без протезирования при длительном синдроме сдавления относительно безопасна в случае компенсации коллатерального кровотока.

Ключевые слова: синдром верхней полой вены, опухоли средостения, рак легкого, резекция верхней полой вены, протезирование полой вены

Для цитирования: Александров ОА, Пикин ОВ, Рябов АБ. Результаты резекции верхней полой вены у больных с опухолевыми заболеваниями легких и средостения. Альманах клинической медицины. 2019;47(8):677-84. doi: 10.18786/20720505-2019-47-080.

Поступила 04.12.2019, доработана 16.12.2019, принята к печати 23.12.2019, опубликована онлайн 27.12.2019

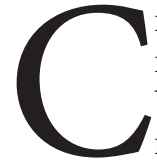
индром верхней полой вены (ВПВ) был впервые описан W. Hunter в 1757 г. [1]. Уменьшение кровотока в системе ВПВ приводит к снижению объема венозной крови в правом предсердии, что обусловливает ряд клинических признаков (расширение вен шеи, отек верхних конечностей, цианоз) и симптомов (головные боли, одышка, кашель, дисфагия) [2].

Нарушение кровотока может быть вызвано наружной компрессией, прямой опухолевой инвазией, тромбозом или неэффективным венозным возвратом вследствие заболеваний, вовлекающих правое предсердие или непосредственно просвет сосуда. Основная роль в этиологии данного синдрома сместилась от туберкулеза и сифилитических аневризм, широко распространенных в начале XX века, в сторону злокачественных опухолей внутригрудной локализации [3]. Ежегодно в США регистрируется 15000 новых случаев синдрома ВПВ, 95\% из которых развиваются вследствие первичных или вторичных опухолевых поражений грудной полости [3]. Одна из важнейших причин развития синдрома ВПВ увеличение частоты использования центральных венозных катетеров и искусственных водителей сердечного ритма [4].

Около 73-97\% всех случаев возникают вследствие развития внутригрудных опухолей, 
компрессии ВПВ самой опухолью либо увеличенными медиастинальными лимфоузлами. В течение длительного времени пациенты с местнораспространенными опухолями грудной клетки считались неоперабельными в связи с плохими непосредственными и отдаленными результатами [5].

Цель исследования - изучение непосредственных результатов резекции ВПВ у больных с опухолевой патологией грудной клетки, разработка алгоритма и определение показаний к выполнению циркулярной резекции ВПВ без протезирования.

\section{Материал и методы}

Исследование представляет собой ретроспективный анализ данных наблюдения 28 пациентов (22 мужчины, 6 женщин; средний возраст 55 (от 21 до 70) лет), которым за 10-летний период (с 2008 по 2018 г.) была проведена резекция ВПВ в ходе хирургического вмешательства по поводу злокачественной опухоли легкого или средостения в отделении торакальной хирургии МНИОИ им. П.А. Герцена. На предоперационном этапе всем пациентам были выполнены стандартные диагностические исследования, позволяющие оценить распространенность опухолевого процесса и функциональные резервы: мультиспиральная компьютерная томография органов грудной клетки и брюшной полости, комплексное ультразвуковое исследование, электрокардиография в 12 отведениях, эхокардиография, спирометрия. При наличии эндобронхиального компонента опухоли выполнялась фибробронхоскопия.

Наиболее достоверным методом диагностики инвазии ВПВ на дооперационном этапе и оценки протяженности поражения мы считаем мультиспиральную компьютерную томографию с внутривенным контрастированием изоосмолярным контрастным препаратом, не вызывающим резкого снижения артериального давления, что на фоне сокращенного притока к сердцу может вызвать сосудистый коллапс. Наиболее четко инвазия ВПВ визуализируется в раннюю венозную фазу исследования. Для определения наличия опухолевого тромба в предсердии и его фиксации необходимо проведение эхокардиографии. В обязательном порядке больным выполнялось ультразвуковое доплеровское сканирование сосудов верхних конечностей и шеи.

При подготовке к операции всем больным проводилась противоотечная терапия. Для обеспечения постоянного венозного доступа
Александров Олег Александрович - мл. науч. сотр. отделения торакальной хирургии'; ORCID: https://orcid. org/0000-0002-4131-9179 $\triangle 125284$, г. Москва, 2-й Боткинский пр-д, 3, Российская Федерация. Тел.: +7 (903) 2753320 E-mail: oleg.alexandrov @icloud.com

Пикин Олег Валентинович - д-р мед. наук, заведующий отделением торакальной хирургии'; ORCID: https:// orcid.org/0000-00016871-6804.

E-mail: pikin_ov@mail.ru

Рябов Андрей Борисович д-р мед. наук, руководитель отдела торакоабдоминальной онкохирургии'; ORCID: https://orcid.org/00000002-1037-2364.

E-mail: ryabovdoc@mail.ru

1 Московский научно-исследовательский онкологический институт имени П.А. Герцена - филиал ФГБУ «Национальный медицинский исследовательский радиологический центр» Минздрава России; 125284, г. Москва, 2-й Боткинский пр-д, 3, Российская Федерация осуществлялась катетеризация бедренной вены, а с целью мониторинга центрального венозного давления - катетеризация подключичной вены со стороны операции.

Этическая экспертиза. Пациенты подписали добровольное информированное согласие на обследование и лечение, а также на публикацию в научных целях персональной медицинской информации в обезличенном виде.

Статистический анализ. Изучены демографические особенности, предоперационные характеристики больных, параметры операций и послеоперационного периода. Для описания количественных переменных рассчитывали медиану (среднее арифметическое), минимальные и максимальные значения. Для описания качественных признаков рассчитывали относительные и абсолютные частоты.

\section{Результаты}

Местнораспространенный рак легкого диагностирован у 19 (67\%) больных, тимома - у 3 (10\%), метастатическое поражение легкого - у 2 (7\%), герминогенная опухоль средостения - у 2 (7\%), рак тимуса - у 1 (3\%), резидуальная лимфома (медиастинальная В-клеточная лимфома) - у 1 (3\%) больного. У большинства больных - в 15 (53\%) случаях - опухолевый процесс носил осложненный характер. Спектр осложнений представлен в табл. 1. В большинстве случаев рака легкого у пациентов отмечалось сочетание различных осложнений, например, таких, как кровохарканье и обтурационный пневмонит. Синдром ВПВ диагностирован у 4 пациентов с опухолями средостения.

Только у 5 (17\%) пациентов не отмечено сопутствующей соматической патологии. Наиболее часто диагностировали гипертоническую болезнь - у 14 больных, хроническую обструктивную болезнь легких - у 12, ишемическуюя болезнь сердца - у 11 пациентов. У 2 пациентов ранее зафиксированы нарушения ритма сердца: в 1 случае - желудочковая экстрасистолия, в другом - пароксизмальная форма фибрилляции предсердий. У 1 пациента диагностирован постинфарктный кардиосклероз, аортокоронарное шунтирование в анамнезе.

Неоадъювантная терапия проведена у 8 (28\%) пациентов (табл. 2). У 2 больных местнораспространенным раком легкого неоадъювантная химиотерапия была прекращена в связи с распадом опухоли. У всех больных опухолями средостения данный вид терапии привел к частичному ответу, уменьшению размеров опухоли более чем на $30 \%$. 
В подавляющем большинстве случаев у 21 (75\%) больного - в качестве оперативного доступа была сделана правосторонняя переднебоковая торакотомия. У 5 (17\%) больных с центральным расположением опухоли средостения проведена полная продольная стернотомия. У 2 (7\%) пациентов в связи с латерализацией опухоли выполнен стерноторакотомный доступ по Grunenwald.

Показанием к резекции ВПВ у 7 (25\%) больных раком легкого послужила инвазия стенки вены метастатически измененными лимфоузлами. В остальных случаях (75\%) отмечена инвазия первичной опухолью.

Краевая резекция ВПВ выполнена у 23 (82\%) пациентов. Среди них в 11 случаях дефект ВПВ ушит при помощи ручного обвивного сосудистого шва, еще 11 больным сделана аппаратная краевая резекция линейным механическим сшивающим аппаратом с последующим укрытием зоны шва. У 1 больного после краевой резекции непрерывность ВПВ восстановлена при помощи фрагмента перикарда. Четырем пациентам проведена циркулярная резекция ВПВ без протезирования. У 1 пациента с периферическим раком верхней доли правого легкого после циркулярной резекции ВПВ осуществлено протезирование ксеноперикардом.

Всем пациентам выполнены комбинированные хирургические вмешательства. Спектр резецированных органов и структур приведен в табл. 3. Частота реконструктивных бронхо-ангиопластических операций, включая резекцию бифуркации трахеи и легочной артерии, составила 46\% (13 случаев). Всем больным раком легкого
Таблица 1. Осложнения опухолевого процесса, диагностированные на предоперационном этапе

\begin{tabular}{lll}
\hline Тип опухоли & Характер осложнений & $\begin{array}{c}\text { Количество } \\
\text { осложнений }\end{array}$ \\
\hline Рак легкого & Кровохарканье & 4 \\
& Ателектаз доли легкого & 2 \\
Обтурационный пневмонит & 3 \\
Рак тимуса & Внутрилегочный абсцесс & 1 \\
Герминогенная опухоль & Распад опухоли & 2 \\
средостения & Синдром ВПВ & 1 \\
Лимфома & Синдром ВПВ & 1 \\
\hline СПВ & Синдром ВПВ & 1 \\
\hline Серхняяполая вена & & \\
\hline
\end{tabular}

ВПВ - верхняя полая вена

выполнена систематическая ипсилатеральная лимфодиссекция.

У 22 пациентов (78\%) течение послеоперационного периода носило неосложненный характер. Двум пациентам с несостоятельностью культи бронха после пневмонэктомии и трахеобронхиального анастомоза, а также циркулярной резекции трахеи выполнено дренирование плевральной полости. В 2 случаях при послеоперационном хилотораксе и внутриплевральном кровотечении потребовалось срочное оперативное вмешательство. Летальный исход зафиксирован у 2 больных с несостоятельностью швов анастомоза после

Таблица 2. Характеристика пациентов в группе неоадъювантного лечения

\begin{tabular}{|c|c|c|c|c|}
\hline № п/п & Пол/возраст & Диагноз & Вид неоадъювантного лечения & Динамика заболевания \\
\hline 1 & $\mathrm{M} / 49$ & Рак легкого IIIа стадии & 1 курс ПХТ & Распад опухоли \\
\hline 2 & $\mathrm{M} / 45$ & Рак легкого IIIа стадии & 3 курса ПХТ & Распад опухоли \\
\hline 3 & ж/52 & Рак легкого IIIa стадии & ДЛТ с СОД 40 Гр & Частичный ответ \\
\hline 4 & $M / 26$ & Герминогенная опухоль средостения & 4 курса ПХТ & Частичный ответ \\
\hline 5 & $M / 21$ & Герминогенная опухоль средостения & 4 курса ПХТ & Частичный ответ \\
\hline 6 & ж/55 & Тимома типа В3 & 4 курса ПХТ & Частичный ответ \\
\hline 7 & $M / 23$ & Рак тимуса & дЛт с СОД 51 Гр & Частичный ответ \\
\hline 8 & $M / 58$ & Лимфома & ХЛТ & Частичный ответ \\
\hline
\end{tabular}

ДЛТ - дистанционная лучевая терапия, Ж - женщина, М - мужчина, ПХТ - полихимиотерапия, СОД - суммарная очаговая доза, ХЛТ - химиолучевая терапия 
Таблица 3. Объем выполненных оперативных вмешательств

\begin{tabular}{ll}
\hline Операция / резецированный орган & Количество больных, абс. (\%) \\
\hline Пневмонэктомия & $14(50)$ \\
Билобэктомия & $2(7)$ \\
Лобэктомия & $8(28)$ \\
Атипичная резекция легкого & $7(25)$ \\
Циркулярная резекция бифуркации трахеи & $5(17)$ \\
Клиновидная резекция бифуркации трахеи & $4(14)$ \\
Краевая резекция легочной артерии & $1(3)$ \\
Диафрагма & $1(3)$ \\
Перикард & $16(57)$ \\
Грудная стенка & $2(7)$ \\
Блуждающий нерв & $8(28)$ \\
Диафрагмальный нерв & $6(21)$ \\
\hline
\end{tabular}

резекции бифуркации трахеи на фоне развития септического шока, таким образом, послеоперационная летальность составила 7\%. Структура послеоперационных осложнений отражена в табл. 4.

\section{Обсуждение}

Среди злокачественных опухолей, приводящих к развитию синдрома ВПВ, наиболее часто встречается немелкоклеточный рак легкого - до $50 \%$ всех случаев, мелкоклеточный рак легкого наблюдается в $22 \%$, лимфома - в $12 \%$, метастазы опухолей других локализаций - в 9\%. На долю самой распространенной злокачественной опухоли средостения - тимомы - приходится лишь $2 \%$ от всех случаев синдрома ВПВ [6]. Однако, если обратить внимание на частоту встречаемости синдрома ВПВ в структуре злокачественных опухолей, на первое место выходят пациенты с лимфопролиферативными заболеваниями. При медиастинальной В-крупноклеточной лимфоме частота развития синдрома ВПВ достигает $57 \%$, при лимфобластной лимфоме - 21\% [3] (табл. 5).

Эпителиальные опухоли вилочковой железы характеризуются инвазивным ростом в 20$30 \%$ случаев. По данным D.J. Cohen и соавт., среди местнораспространенных тимом инвазия плевры отмечается в $30 \%$, перикарда $-25 \%$, легкого - $8 \%$, возвратного гортанного нерва - 4\% случаев [6].

Верхняя полая вена расположена в висцеральном компартменте средостения и окружена ригидными структурами: грудиной, трахеей, правым главным бронхом, аортой и правой легочной артерией. Тонкая сосудистая стенка,

Таблица 4. Структура послеоперационных осложнений

\begin{tabular}{|c|c|c|c|c|c|}
\hline № $п / п$ & Пол/возраст & Диагноз & Объем операции & Осложнения & $\begin{array}{l}\text { Степень тяжести } \\
\text { oсложнений по } \\
\text { Clavien - Dindo }\end{array}$ \\
\hline 1 & $M / 45$ & $\begin{array}{l}\text { Рак легкого, уст } \mathrm{N}_{1} \mathrm{M}_{0} \text {, IIIа стадия, } \\
3 \text { курса ПХТ }\end{array}$ & $\begin{array}{l}\text { ПЭ справа с циркулярной } \\
\text { резекцией бифуркации трахеи, } \\
\text { перикарда, МЛАЭ }\end{array}$ & $\begin{array}{l}\text { Пароксизм фибрилляции } \\
\text { предсердий, несостоятельность } \\
\text { трахеобронхиального анастомоза }\end{array}$ & Illa \\
\hline 2 & $M / 60$ & Рак легкого, $\mathrm{pT}_{3} \mathrm{~N}_{2} \mathrm{M}_{0}$, IIIa стадия & $\begin{array}{l}\text { ПЭ справа, резекция блуждающего } \\
\text { нерва, МЛАЭ }\end{array}$ & Несостоятельность культи бронха & Illa \\
\hline 3 & $M / 53$ & Рак легкого, $\mathrm{pT}_{4} \mathrm{~N}_{2} \mathrm{M}_{0}$, Illb стадия & $\begin{array}{l}\text { ПЭ справа с клиновидной } \\
\text { резекцией бифуркации трахеи, } \\
\text { МЛАЭ }\end{array}$ & Внутриплевральное кровотечение & IIIb \\
\hline 4 & $M / 63$ & Рак легкого, $\mathrm{pT}_{2 \mathrm{a}} \mathrm{N}_{2} \mathrm{M}_{0}$, IIla стадия & $\begin{array}{l}\text { ПЭ справа, клиновидная резекция } \\
\text { бифуркации трахеи, перикарда, } \\
\text { МЛАЭ }\end{array}$ & Хилоторакс & IIIb \\
\hline 5 & $M / 63$ & Рак легкого, с $\mathrm{T}_{3} \mathrm{~N}_{1} \mathrm{M}_{0}$, IIla стадия & $\begin{array}{c}\text { ВЛЭ справа с клиновидной } \\
\text { резекцией бифуркации трахеи, } \\
\text { перикарда, диафрагмального } \\
\text { и блуждающего нервов, МЛАЭ }\end{array}$ & $\begin{array}{l}\text { Пневмония оперированного легкого, } \\
\text { несостоятельность швов анастомоза } \\
\text { бронха }\end{array}$ & V \\
\hline 6 & $M / 57$ & Рак легкого, $\mathrm{pT}_{3} \mathrm{~N}_{2} \mathrm{M}_{0}$, IIla стадия & $\begin{array}{l}\text { ПЭ справа с циркулярной } \\
\text { резекцией бифуркации трахеи, } \\
\text { блуждающего нерва, МЛАЭ }\end{array}$ & $\begin{array}{l}\text { Несостоятельность } \\
\text { трахеобронхиального анастомоза }\end{array}$ & V \\
\hline
\end{tabular}

ВЛЭ - верхняя лобэктомия, М - мужчина, МЛАЭ - медиастинальная лимфаденэктомия, ПЭ - пульмонэктомия 
Таблица 5. Частота развития синдрома верхней полой вены в структуре злокачественных опухолей $[3,7]$

\begin{tabular}{|c|c|c|c|}
\hline Тип опухоли & Частота, \% & Количество пациентов, n & Исследование \\
\hline Медиастинальная В-крупноклеточная лимфома & 57 & $(17 / 30)$ & Lazzarino M. и соавт. [8] \\
\hline Лимфобластная лимфома & 21 & $(11 / 56)$ & Perez-Soler R. и соавт. [9] \\
\hline Герминогенные опухоли & 20 & $(9 / 45)$ & Holbert B.L. и соавт. [10] \\
\hline Мелкоклеточный рак & 10 & $(439 / 4405)$ & Rowell N.P. и соавт. [11] \\
\hline Тимома & 11 & $(12 / 104)$ & Yagi К. и соавт. [12] \\
\hline Диффузная крупноклеточная лимфома & 7 & $(23 / 339)$ & Perez-Soler R. и соавт. [9] \\
\hline Немелкоклеточный рак & 1,7 & $(49 / 2902)$ & Rowell N.P. и соавт. [11] \\
\hline
\end{tabular}

легкая сжимаемость обусловливают предрасположенность ВПВ к сдавлению извне при различных опухолевых процессах. В случае компрессии, нарушения ламинарности кровотока инициируется развитие коллатерального кровообращения, по которому осуществляется венозный отток от верхней половины туловища. Обычно моменту непосредственной инвазии предшествует длительный период наружной компрессии, в течение которого успевает сформироваться коллатеральный венозный отток, развивающийся по следующим путям:

- через систему непарной вены (при условии сохранения ее проходимости);

- через систему внутренних грудных вен и их анастомозы с верхними и нижними надчревными венами в систему наружных подвздошных вен;

- через позвоночные вены в нижнюю полую вену [13].

Постоянно повышенное давление в системе ВПВ в течение нескольких недель или даже месяцев приводит к прогрессивному расширению и развитию сети коллатерального кровотока. За счет этого механизма к моменту выполнения хирургического вмешательства не всегда развивается клинически значимый синдром ВПВ. Среди наших пациентов синдром ВПВ был диагностирован у 4 (14\%) больных с опухолями средостения. В исследовании L. Spaggiari и соавт. синдром ВПВ был диагностирован у 8 (11\%) из 72 пациентов. У больных раком легкого на первый план выходили такие симптомы, как кровохарканье и одышка при физической нагрузке, связанные с ростом первичной опухоли легкого [14].

Существует множество различных опций лечения синдрома ВПВ в зависимости от вызвавших его причин, включая лучевую терапию, химиотерапию, тромболизис, прием антикоагулянтов, эндоваскулярные процедуры (баллонная ангиопластика, стентирование), хирургическое вмешательство. Большая часть пациентов с синдромом ВПВ опухолевого генеза могут быть излечены от симптомов заболевания паллиативной химиотерапией или лучевым лечением. Такой клинический эффект может развиваться за счет усиления коллатерального кровообращения либо частичной реканализации просвета сосуда.

Традиционно опухоли торакальной локализации с инвазией в магистральные сосуды средостения считались неоперабельными в связи с плохими непосредственными и долгосрочными результатами. Однако выполнение радикальных хирургических вмешательств увеличивает отдаленную общую и безрецидивную выживаемость пациентов [15]. Десятилетняя выживаемость при тимоме III стадии по Masaoka увеличивается с 31-35\% при объеме операции R1-R2 до 75-94\% при R0-резекции [16]. При таких обнадеживающих результатах попытки выполнения расширенно-комбинированных хирургических вмешательств представляются онкологически оправданными.

В 1970-1980 гг. на основании экспериментальных данных и единичных клинических наблюдений была продемонстрирована возможность выполнения расширенных оперативных вмешательств с резекцией и протезированием сосудов при опухолях легкого и средостения [17]. В 2007 г. L. Spaggiari и соавт. представили опыт резекции ВПВ у 119 пациентов с опухолями легкого и средостения. Послеоперационная летальность составила 7,7\%, частота послеоперационных осложнений - 23\%, что коррелирует с результатами, полученными в нашем исследовании (7 и $12 \%$ соответственно) [18]. 
$\mathrm{y}$ пациентов с инвазией менее $2 / 3$ окружности, ограниченной инфильтрацией стенки ВПВ, резекция может быть выполнена в едином блоке с опухолью после тангенциального отжатия сосуда с последующим обвивным ручным сосудистым швом. Наложение сосудистого зажима по возможности должно быть выполнено выше впадения дуги непарной вены, чтобы обеспечить коллатеральный кровоток, минимизируя риск повреждения головного мозга. При невозможности отжатия ВПВ выше дуги непарной вены и длительности перекрытия кровотока свыше 60 минут рекомендуется выполнение обходного сосудистого шунта. Ограничение кровотока в течение 105 минут и выше приводит к венозному стазу и неизбежному повреждению головного мозга [19].

В случае когда после пробного пережатия ВПВ давление в системе возрастает выше 40 мм вод. ст., показано выполнение шунтирующей операции [13]. При интраоперационном развитии острого синдрома ВПВ необходимо формирование временного шунта между одной из плечеголовных вен и ушком правого предсердия. Решение о циркулярной резекции ВПВ без протезирования мы принимали после предварительного пережатия ее притоков на 1,5 часа и в отсутствие развития острого синдрома ВПВ во время операции, что свидетельствовало о компенсации коллатерального кровообращения.

При необходимости краевой резекции ВПВ в качестве альтернативы возможно использование сосудистого аппарата, в этом случае резекция выполняется без предварительного отжатия.

Смертность от осложнений, связанных непосредственно с протезированием ВПВ, составляет от 4,5 до $12 \%[14,16]$. Одно из наиболее грозных осложнений - тромбоз с последующей тромбоэмболией легочной артерии. По данным P.G. Dartevelle и соавт., тромбоз протеза в течение 3 лет наблюдается в 86\% случаев [19]. Часто это связано с техническими аспектами выполнения анастомоза, неправильным подбором типа и диаметра протеза.

Риск развития послеоперационных осложнений зависит от ряда факторов. При краевой резекции ВПВ ранний тромбоз бывает связан с избыточным удалением стенки сосуда, деформацией просвета сосудистым швом. По данным L. Spaggiari и соавт., данное осложнение развилось в 2,5\% (2/80) случаев, 1 пациент был повторно оперирован в объеме протезирования ВПВ заплатой из подкожной вены бедра в связи с быстрым ухудшением симптомов, связанных с синдромом ВПВ [2]. В нашей серии наблюдений мы не столкнулись с подобным осложнением после краевой резекции ВПВ.

Гораздо чаще осложнения встречаются у пациентов, которым выполнена циркулярная резекция ВПВ с последующим протезированием. При развитых сосудистых коллатералях протезирование приводит к снижению объема циркулирующей крови по протезу с последующим тромбозом [18]. По данным литературы, тромбоз протеза встречается в 14-24\% случаев. Однако его истинная частота может быть недооценена в связи с отсутствием катамнестических данных, неадекватным послеоперационным обследованием. В исследовании G.D. Lee и соавт. у 8 (50\%) из 16 пациентов, которым выполнялась венография, был диагностирован тромбоз протеза в отдаленном послеоперационном периоде [20]. У 4 из 8 пациентов в связи с развитием острого синдрома ВПВ выполнено обходное шунтирование. У пациентов с клинически значимым тромбозом для стимуляции развития коллатералей и снижения интенсивности симптомов в качестве первой линии терапии показано назначение антикоагулянтов. Кроме того, может быть полезным назначение кортикостероидов, диуретиков. Однофакторный анализ, проведенный авторами, позволил выявить повышенный риск окклюзии протеза при анастомозе с левой плечеголовной веной и ушком правого предсердия [20]. При таких условиях формирования анастомоза происходит угловое искривление протеза, рекомендуется воздержаться от протезирования в случае выраженного коллатерального кровотока.

Показаниями к циркулярной резекции ВПВ без протезирования считаем длительно существующий опухолевый тромбоз, выраженное развитие коллатерального кровотока. Перевязка ВПВ без протезирования не изменяет клинической картины синдрома ВПВ, однако позволяет существенно повысить радикальность онкологического этапа операции. В нашем исследовании среди 4 пациентов с опухолями средостения, которым выполнена циркулярная резекция ВПВ без протезирования, мы не зафиксировали ухудшения данного синдрома в послеоперационном периоде.

В вопросе о роли антикоагулянтной терапии после протезирования нет единого мнения. Y. Shintani и соавт. предположили, что длительная антикоагулянтная терапия (дольше 6 месяцев) может быть необходима у пациентов с реконструкцией обеих плечеголовных вен для снижения вероятности позднего тромбирования [21]. К повышенному риску тромбообразования в этих 
условиях приводит низкая интенсивность кровотока в данных сосудах. I.C. Okereke и соавт. привели данные 38 пациентов, которым была выполнена реконструкция системы ВПВ при помощи обходного РТFЕ-шунта. В послеоперационном периоде назначалась монотерапия ацетилсалициловой кислотой, при этом авторы не наблюдали повышения частоты тромбоза [22]. В исследовании G.D. Lee и соавт. в послеоперационном периоде назначался варфарин на период от 3 до 6 месяцев. При его отмене назначалась ацетилсалициловая кислота с клопидогрелом или без него. Однако данная группа авторов наблюдала тромбозы после отмены варфарина на фоне приема антиагрегантов [20].

\section{Заключение}

Резекция ВПВ может быть безопасно выполнена у пациентов с первичными опухолями средостения и легкого. При длительно существующем синдроме ВПВ развившиеся кава-кавальные анастомозы берут на себя значительную функцию ВПВ. Для повышения радикальности операции правая и левая плечеголовные вены могут быть пересечены без реконструкции при достаточности коллатерального кровотока. Циркулярная резекция ВПВ без протезирования при длительном синдроме сдавления в случае компенсации коллатерального кровотока относительно безопасна. (ङ)

\section{Дополнительная информация}

Финансирование

Работа проведена без привлечения дополнительного финансирования со стороны третьих лиц.

Конфликт интересов

Авторы декларируют отсутствие явных и потенциальных конфликтов интересов, связанных с публикацией настоящей статьи.

\begin{abstract}
Участие авторов
О.А. Александров - поиск и анализ литературы, обработка исходного материала, написание текста; О.В. Пикин - концепция и дизайн статьи, редактирование, финальное утверждение рукописи; А.Б. Рябов концепция и дизайн статьи, редактирование, финальное утверждение рукописи. Все авторы внесли существенный вклад в проведение исследования и подготовку статьи, прочли и одобрили финальную версию перед публикацией.
\end{abstract}

\section{Литература / References}

1.Danias PG, Pipilis AG. Superior vena cava syndrome: 1757-2007. Hellenic J Cardiol. 2007;48(6):366-7.

2. Spaggiari L, Leo F, Veronesi G, Solli P, Galetta D, Tatani B, Petrella F, Radice D. Superior vena cava resection for lung and mediastinal malignancies: a single-center experience with 70 cases. Ann Thorac Surg. 2007;83(1):223-9. doi: 10.1016/j.athoracsur.2006.07.075.

3. Wilson LD, Detterbeck FC, Yahalom J. Clinical practice. Superior vena cava syndrome with malignant causes. N Engl J Med. 2007;356(18): 1862-9. doi: 10.1056/NEJMcp067190.

4. Venuta F, Rendina EA. Superior vena cava resection and reconstruction. Eur J Cardiothorac Surg. 2012;41(5):1177-8. doi: 10.1093/ejcts/ ezr266.

5. Jones DR. Technique of superior vena cava resection for lung carcinomas. Oper Tech Thorac Cardiovasc Surg. 2008;13(4):274-82. doi: 10.1053/j.optechstcvs.2009.01.002.

6. Cohen DJ, Ronnigen LD, Graeber GM, Deshong JL, Jaffin J, Burge JR, Zajtchuk R. Management of patients with malignant thymoma. J Thorac Cardiovasc Surg. 1984;87(2): 301-7.

7. Inaco Cirino LM, Ferreira Coelho R, Dias da Rocha I, Pinheiro de Senna Nogueira Batista B. Treatment of superior vena cava syndrome. J. Bras. Pneumol. 2005;31(6). doi: 10.1590/S180637132005000600013.

8. Lazzarino M, Orlandi E, Paulli M, Boveri E, Morra E, Brusamolino E, Kindl S, Rosso R, Astori C, Buonanno MC. Primary mediastinal B-cell lymphoma with sclerosis: an aggressive tumor with distinctive clinical and pathologic features. J Clin Oncol. 1993;11(12):2306-13. doi: 10.1200/JCO.1993.11.12.2306.

9. Perez-Soler R, McLaughlin P, Velasquez WS, Hagemeister FB, Zornoza J, Manning JT, Fuller LM, Cabanillas F. Clinical features and results of management of superior vena cava syndrome secondary to lymphoma. J Clin Oncol. 1984;2(4):260-6. doi: 10.1200/ JCO.1984.2.4.260.

10. Holbert BL, Libshitz HI. Superior vena caval syndrome in primary mediastinal germ cell tumors. Can Assoc Radiol J. 1986;37(3):182-3.

11. Rowell NP, Gleeson FV. Steroids, radiotherapy, chemotherapy and stents for superior vena caval obstruction in carcinoma of the bronchus: a systematic review. Clin Oncol (R Coll Radiol). 2002;14(5):338-51. doi: 10.1053/ clon.2002.0095.

12. Yagi $K$, Hirata T, Fukuse $T$, Yokomise $H$, Inui $K$, Ike $\mathrm{O}$, Mizuno $\mathrm{H}$, Aoki $\mathrm{M}$, Hitomi S, Wada $\mathrm{H}$. Surgical treatment for invasive thymoma, especially when the superior vena cava is invaded. Ann Thorac Surg. 1996;61(2):521-4. doi: 10.1016/0003-4975(95)00983-3.

13. Пикин ОВ, Трахтенберг АХ, Колбанов КИ, Глушко ВА, Казакевич ВИ, Амиралиев АМ, Вурсол ДА, Кирсанова ОН. Циркулярная резекция верхней полой вены без протезирования у больных с опухолью средостения, осложненной синдромом медиастинальной компрессии. Онкохирургия. 2013;5(2): 60-6. [Pikin O, Trakhtenberg AKh, Kolbanov KI
Glushko VA, Kazakevich VI, Amiraliev AM, Vursol DA, Kirsanova ON. [Circumferential inferior vena cava resection without prosthesis in patients with mediastinal tumor complicated by mediastinal compression syndrome]. Oncosurgery. 2013;5(2):60-6. Russian.]

14. Spaggiari $L$, Thomas $P$, Magdeleinat $P$, Kondo H, Rollet G, Regnard JF, Tsuchiya R, Pastorino U. Superior vena cava resection with prosthetic replacement for non-small cell lung cancer: long-term results of a multicentric study. Eur J Cardiothorac Surg. 2002;21(6): 1080-6. doi: 10.1016/s1010-7940(02)00175-6.

15. Александров ОА, Рябов АБ, Пикин ОВ. Тимома (обзор литературы). Сибирский онкологический журнал. 2017;16(4):76-83. doi: $\quad$ 10.21294/1814-4861-2017-16-4-76-83. [Alexandrov OA, Ryabov AB, Pikin OV. [Thymoma (review of the literature)]. Siberian Journal of Oncology. 2017;16(4):76-83. Russian. doi: 10.21294/1814-4861-2017-16-4-76-83.]

16. Fujisawa T, Yamaguchi $Y$, Baba $M$, Shiba $M$, Yamakawa H, Kimura H, Ogawa T, Kadoyama C, Yusa T, Iwai N. [Significance of superior vena cava reconstruction with EPTFE grafts in the surgical treatment of superior and anterior mediastinal invasive malignant tumors]. Nihon Kyobu Shikkan Gakkai Zasshi. 1990;28(4): 612-6. Japanese.

17. Scherck JP, Kerstein MD, Stansel HC Jr. The current status of vena caval replacement. Surgery. 1974;76(2):209-33.

18. Spaggiari L, Magdeleinat P, Kondo H, Thomas $\mathrm{P}$, Leon ME, Rollet G, Regnard JF, Tsuchiya R, 
Pastorino U. Results of superior vena cava resection for lung cancer. Analysis of prognostic factors. Lung Cancer. 2004;44(3):339-46. doi: 10.1016/j.lungcan.2003.11.010.

19. Dartevelle PG, Chapelier AR, Pastorino U, Corbi $P$, Lenot B, Cerrina J, Bavoux EA, Verley JM, Neveux JY. Long-term follow-up after prosthetic replacement of the superior vena cava combined with resection of mediastinal-pulmonary malignant tumors. J Thorac Cardiovasc Surg. 1991;102(2):259-65.
20. Lee GD, Kim HR, Choi SH, Kim YH, Kim DK, Park SI. Prosthetic graft interposition of the brachiocephalic veins or superior vena cava combined with resection of malignant tumours: graft patency and risk factors for graft occlusion. J Thorac Dis. 2016;8(1):61-7. doi: 10.3978/j.issn.2072-1439.2016.01.07.

21. Shintani $Y$, Ohta $M$, Minami $M$, Shiono $H$, Hirabayashi $H$, Inoue $M$, Matsumiya $G$, Matsuda $H$. Long-term graft patency after replacement of the brachiocephalic veins combined with resection of mediastinal tumors. J Thorac Cardiovasc Surg. 2005;129(4):809-12. doi: 10.1016/j. jtcvs.2004.05.001.

22. Okereke IC, Kesler KA, Rieger KM, Birdas TJ, Mi D, Turrentine MW, Brown JW. Results of superior vena cava reconstruction with externally stented-polytetrafluoroethylene vascular prostheses. Ann Thorac Surg. 2010;90(2):3837. doi: 10.1016/j.athoracsur.2010.04.004.

\title{
Results of superior vena cava resection in patients with lung and mediastinal tumors
}

\author{
O.A. Alexandrov' • O.V. Pikin' • A.B. Ryabov'
}

Background: Thoracic tumors involving the superior vena cava (SVC) are common in the practice of a thoracic surgeon treating cancer patients. Extended combined procedures that allow for complete removal of the tumor improves overall and disease-free survival and as such are justified from an oncologist's perspective. In some patients, due to a long-standing SVC syndrome, the development of venous collaterals would increase the early postoperative risk of thrombus formation in the prosthesis. In such a case, it is possible to perform circular SVC resection without subsequent prosthetic replacement. Aim: To evaluate the short-term results of SVC resection in patients with chest tumors, to develop an algorithm and to identify the patient group in whom circular SVC without prosthetic replacement is feasible. Materials and methods: Twenty eight (28) patients were included into the study (22 men and 6 women, with the mean age of 55 [range, 21 to 70 years]; all of them had undergone SVC resection within the intervention for a lung or mediastinal malignancy for 10 years (from 2008 to 2018) in the Department of Thoracic Surgery, Moscow Research Institute of Oncology named after P.A. Herzen. We analyzed their short-term results of the procedures, the postoperative course, and technical particulars of the procedures. Results: Locally advanced lung cancer was diagnosed in $19(67 \%)$ of the patients, thymoma in $3(10 \%)$, lung metastatic disease in 2 (7\%), germ-cell mediastinal tumors in 2 (7\%), thymus cancer in $1(3 \%)$, and residual lymphoma in $1(3 \%)$ patient. In the majority of the patients ( 15 cases, $53 \%$ ), the complicated clinical course had been diagnosed before surgery. In 4 patients with protracted SVC syndrome, we performed circular resection without any prosthetic replacement. In 22 patients (78\%), the postoperative course was uneventful. Postoperative mortality was $7 \%$. Conclusion: SVC resection can be safely performed in patients with primary mediastinal and lung tumors. With a long-standing SVC syndrome, the newly developed cava-caval anastomoses can provide significant functional support; in such patients with compensatory collateral blood flow, the circular SVC resection without prosthetic replacement is relatively safe.

Key words: superior vena cava syndrome, mediastinal tumor, lung cancer, superior vena cava resection, superior vena cava prosthesis

For citation: Alexandrov OA, Pikin OV, Ryabov AB. Results of superior vena cava resection in patients with lung and mediastinal tumors. Almanac of Clinical Medicine. 2019;47(8):677-84. doi: 10.18786/20720505-2019-47-080

Received 4 December 2019; revised 16 December 2019; accepted 23 December 2019; published online 27 December 2019

\section{Conflict of interests}

The authors declare no conflict of interests.

\section{Authors' contributions}

O.A. Alexandrov, literature search and analysis, data management, text writing; O.V. Pikin, the study concept and design, text writing, approval of the final version of the manuscript; A.B. Ryabov, the study concept and design, text writing, approval of the final version of the manuscript. All the authors have made their significant contributions into the study conduct and article writing, have read and approved its final version before the publication.

Oleg A. Alexandrov - Junior Research Fellow, Department of Thoracic Surgery'; ORCID: https:// orcid.org/0000-0002-4131-9179 $\triangle 32^{\text {nd }}$ Botkinskiy proezd, Moscow, 125284 , Russian Federation. Tel.: +7 (903) 2753320. E-mail: oleg.alexandrov@icloud.com

Oleg V. Pikin - MD, PhD, Head of Department of Thoracic Surgery'; ORCID: https://orcid.org/00000001-6871-6804. E-mail: pikin_ov@mail.ru

Andrey B. Ryabov - MD, PhD, Head of Department of Thoracoabdominal Oncosurgery'; ORCID: https:// orcid.org/0000-0002-1037-2364.

E-mail: ryabovdoc@mail.ru
P. Herzen Moscow Oncology Research Institute Branch of the National Medical Research Radiological Centre; $32^{\text {nd }}$ Botkinskiy proezd, Moscow, 125284, Russian Federation 